\title{
Procedural Skills of a General Internist - Informed by the Front Line
}

Rodrigo B Cavalcanti MD, MSc, FRCPC, Amy C Hendricks MD, FRCPC, Sharon E Card MD, MSc, FRCPC

\begin{abstract}
About the Authors
Rodrigo B Cavalcanti is with the Division of General Internal Medicine at the University of Toronto. Toronto, ON. Amy C Hendricks is in General Internal Medicine in Antigonish, Nova Scotia. Sharon E Card is with the Division of General Internal Medicine at the University of Saskatchewan, Saskatoon, SK.
\end{abstract}

Correspondence may be directed to Sharon E. Card: sharon.card@usask.ca

Submitted: January 12, 2017. Accepted: August 1, 2017. Published November 7, 2017.

\begin{abstract}
Debate has occurred over many years regarding the ideal procedural skill set for a graduate of a General Internal Medicine (GIM) training program. A mixed methods study was used to establish a list of mandatory and selective procedural skills for all graduates of a 2-year PGY4/5 GIM subspecialty training program. This list was informed by previous literature, a survey of Canadian Society of Internal Medicine (CSIM) members, and a roundtable discussion at the October 2015 CSIM meeting in Prince Edward Island. The study illustrates the remarkable diversity of practice profiles and procedural skills performed by general internists in Canada.

Résumé

Depuis nombre d'années, l’ensemble idéal d'habiletés qu'un diplômé d'un programme de médecine interne générale (MIG) doit maîtriser fait l’objet de débats. Une étude à méthodologie mixte a été utilisée pour dresser une liste d'habiletés particulières et obligatoires que doivent maîtriser tous les diplômés de $4^{\mathrm{e}}$ et de $5^{\mathrm{e}}$ année d'un programme comportant deux ans de surspécialité en médecine interne générale. Cette liste a été établie à partir de documentation existante, d'un sondage auprès des membres de la Société canadienne de médecine interne (SCMI) et d'une table ronde tenue lors du Congrès de la Société en octobre 2015 à l'Île-du-Prince-Édouard. Létude montre la remarquable diversité des profils de pratique et des habiletés déployées par les internistes généraux au Canada.
\end{abstract}

Canadian General Internists have had longstanding passionate debates regarding which procedures should be performed competently by graduates of General Internal Medicine (GIM) programs. ${ }^{1-4}$ Previous studies have shown a diversity of procedures performed in practice, with insufficient consensus as to which procedures should be routinely learned by GIM graduates. ${ }^{3,4}$ Concurrently literature suggests that Canadian GIM Graduates are not sufficiently prepared to perform procedural skills in practice. $^{3}$

GIM training is now defined as a 2-year PGY 4/5 program which builds on the "core" internal medicine training programs. ${ }^{5}$ Current (2016) objectives of training for Internal Medicine (IM) ${ }^{5}$ indicate that all IM residents must be competent in the procedures in Table 1. Additionally, the GIM (PGY 4/5) 5 programs mandate competence in further procedures. (Table 1). As of 2016, these would be considered mandatory procedural skills for ALL GIM graduates and therefore each GIM program must be able to provide training for proficiency in the skills in Table 1.

The GIM documents were deliberately written to allow flexibility in training, ensuring that GIM trainees have the opportunity to train in additional procedures tailored to their future practice setting. Operationally this has been difficult to implement for 2 major reasons: (1) many residents do not know their future practice location in sufficient time to plan procedural training and (2) programs have had difficulty developing multiple elective training opportunities which may or may not be used.

The Royal College of Physicians and Surgeons of Canada (RCPSC) has launched the Competence by Design project with 
competency based medical education being anticipated to be initiated in GIM programs as of 2018. ${ }^{6}$ Competence by Design will focus training on outcomes ensuring that graduates are prepared to meet the needs of their future patients and communities. ${ }^{6}$ As part of this process, the GIM Specialty Committee is obtaining as much data as possible to inform desired educational outcomes for GIM graduates. A mixed method study was developed to provide the RCPSC GIM Specialty Committee with data on which to base decisions regarding which procedural skills should be taught in GIM PGY 4/5 residencies as of 2018. The primary objective was to develop a list of procedural skills for GIM training programs that is separated into the following categories:

- Mandatory skills - all graduates of all GIM programs must be competent in these procedures.

- Selective skills - community need requires a sufficient number of GIM graduates to be proficient in these skills, such that all GIM programs must offer the training.

- Elective skills - a few graduates require these skills to fill community need, but not all GIM programs must offer the training. These procedural skills would not be written into RCPSC documents, but program directors and residents would need to be aware they may be required.
The study results were triangulated with previous literature on procedural training for Canadian General Internists ${ }^{3,4}$ to allow the GIM Specialty Committee (national standard-setting body) to come to a final determination of procedural training standards for Canadian General Internists.

\section{Methods}

This was a mixed methods study triangulating data from multiple sources. The study was considered exempt by the University of Saskatchewan research ethics board. The overall intent of the project was to seek the opinions of practicing general internists, GIM program directors and the GIM RCPSC Specialty Committee (the national body which develops standards) regarding which procedures should be learned.

Previous Canadian studies ${ }^{3,4}$ were reviewed in terms of scope of practice and prevalence of procedural skills performed by Canadian General Internists. The initial cohort of Practice Eligibility route applicants for GIM certification was reviewed as to which procedural skills were self- reported to be performed by Canadian General Internists. An electronic survey of Canadian Society of Internal Medicine (CSIM) Members was performed in fall 2015. The data from the preliminary survey was collated and presented at a plenary session at the October 2015 CSIM

Table 1. Procedural Skills in Internal Medicine and General Internal Medicine Objectives of Training as of January 2016

\section{INTERNAL MEDICINE PROCEDURES (2016)}

Demonstrate effective, appropriate, and timely performance of the following diagnostic and therapeutic procedures relevant to Internal Medicine including indications, benefits, risks and interpretation of results

- Establishing an airway, bag and mask ventilation, mouth-to-mask ventilation, and use of hand-held resuscitators

- Invasive and non-invasive mechanical ventilation

- Insertion and care of peripheral arterial catheters

- Venous access including central line placement in elective and emergency situations

- Cardiopulmonary resuscitation

- Combined assisted ventilation and external cardiac compression in one-person and two-person rescue

- External cardiac defibrillation

- Endotracheal intubation

- Emergency transcutaneous pacing

- Diagnosing and managing life-threatening cardiac arrhythmias

- Electrocardiograms

- Diagnostic and therapeutic thoracentesis

- Diagnostic and therapeutic abdominal paracentesis

- Lumbar puncture

- Knee arthrocentesis

\section{GENERAL INTERNAL MEDICINE PROCEDURES (2016)}

- Demonstrate effective, appropriate, and timely performance of diagnostic and therapeutic procedures relevant to General Internal Medicine:

- Exercise stress testing

- Ambulatory blood pressure monitoring

- Ambulatory electrocardiogram (Holter monitor)

- Invasive mechanical ventilation

- Non-invasive mechanical ventilation

(http://www.royalcollege.ca/portal/page/portal/rc/public) ${ }^{5}$ 
Table 2. Summary Table of Sources Reviewed to Come to Final Consensus

\begin{tabular}{|c|c|c|}
\hline Source & Limitations/Assets & Weighting \\
\hline $\begin{array}{l}\text { BMC Medical Education 2006; 6;56 } \\
\text { Card SE, Snell L and BD O'Brien }\end{array}$ & $\begin{array}{l}\text { Mailed survey via CSIM } \\
\text { Sent via GIM PDs to graduates of GIM programs } 1993-2001 \text {. } \\
\text { Limitation - done prior to RCPSC recognition of GIM so } \\
\text { heterogeneous population of respondents. } \\
\text { Response rate } 39 \%\end{array}$ & $\begin{array}{l}\% \text { performance at least once/month. } \\
M>50 \% ; S>30 \% ; E<30 \% \\
\text { Importance Rating }(\% 4 \text { or } 5 / 5) \\
M>50 \text { \& performed }>50 ; S>50 \& \\
\text { performed }<50 ; E<50 \text {. }\end{array}$ \\
\hline $\begin{array}{l}\text { BMC Research Notes 2011; 4:480 } \\
\text { Card SE, PausJenssen A; Ottenbreit R. }{ }^{4}\end{array}$ & $\begin{array}{l}\text { Online survey of } 157 \text { practicing GIM. Perceptions of importance. In } \\
\text { practice average of } 15 \text { years. All provinces, territories represented. } \\
\text { Diverse practice types. }\end{array}$ & $\begin{array}{l}\text { Importance for practice }(\% 4 \text { or } 5 / 5) \\
\text { Publication only lists those }>50 \% \\
M>50 \% \text {. }\end{array}$ \\
\hline PER Sub First Cohort Data & $\begin{array}{l}\text { Individuals applied to write the inaugural GIM certification } \\
\text { examination. "Gold Standard' cohort but write in questions, self- } \\
\text { audit therefore likely underestimates significantly. }\end{array}$ & $\begin{array}{l}\text { Performance in practice. } \\
M>20 \% ; S>5 \% ; E<5 \% \text {. }\end{array}$ \\
\hline $\begin{array}{l}\text { Final online CSIM Survey November } \\
2015\end{array}$ & $\begin{array}{l}150 \text { responses. Canada wide participation. Urban and rural } \\
\text { practices. } 125 \text { full members. } 11 \% \text { response rate. }\end{array}$ & $\begin{array}{l}\% \text { Performing procedure. } \\
M>40 \% ; S>20 \% ; E<20 \% \\
\text { Importance rating for Trainees (many + all). } \\
M>80 \% ; S>60 \% ; E<60 \%\end{array}$ \\
\hline $\begin{array}{l}\text { Discussion at CSIM October } 2015 \\
\text { meeting using preliminary online } \\
\text { CSIM survey data }\end{array}$ & 150 participants. Diverse audience. & $\begin{array}{l}\text { Used to define, discuss, and clarify } \\
\text { consensus and divergence of opinion using } \\
\text { the online survey preliminary data. }\end{array}$ \\
\hline $\begin{array}{l}\text { Expert Stakeholder Validation In } \\
\text { Person }\end{array}$ & $\begin{array}{l}\sim 25 \text { expert stakeholders - GIM regional representatives, GIM } \\
\text { examination committee representatives, GIM program Directors }\end{array}$ & $\begin{array}{l}\text { Final Delphi voting - GIM Specialty } \\
\text { meeting February } \\
\text { Consensus }>80 \%\end{array}$ \\
\hline $\begin{array}{l}\text { Online Voting of Expert Stakeholders } \\
\text { post meeting }\end{array}$ & $\begin{array}{l}\sim 25 \text { expert stakeholders - GIM regional representatives, GIM } \\
\text { examination committee representatives, GIM program Directors }\end{array}$ & $\begin{array}{l}\text { Voted only on areas without consensus } \\
\text { as defined at final expert stakeholder } \\
\text { validation meeting. }\end{array}$ \\
\hline
\end{tabular}

$\mathrm{M}=$ mandatory $; \mathrm{S}=$ selective; $\mathrm{E}=$ elective.

Table 3. Mandatory GIM Graduate Procedural Skills

Procedures for which there is a consensus across multiple data areas that the skill should be mandatory. *

\begin{tabular}{|l|}
\hline ECG Interpretation \\
\hline Exercise Stress Testing \\
\hline Holter Interpretation \\
\hline Thoracentesis \\
\hline PFT Interpretation \\
\hline Paracentesis \\
\hline Central Venous Catheter Insertion \\
\hline Arterial Line Insertion \\
\hline Endotracheal Tube Insertion \\
\hline Mechanical Ventilation \\
\hline Non-invasive Positive-Pressure Ventilation \\
\hline \begin{tabular}{l} 
Ultrasound Guided Bedside Procedures (thoracentesis; paracentesis; \\
central venous lines) \\
\hline Lumbar Puncture \\
\hline Knee Joint Aspiration \\
\hline *Note ACLS/CPR was presumed to be a mandatory skill. \\
*Note Ambulatory Blood Pressure Interpretation will also be a mandatory skill but had \\
insufficient data for triangulation.
\end{tabular} \\
\hline
\end{tabular}

Table 4. Selective GIM Graduates Procedural Skills

Procedures for which there is a consensus across multiple data areas they should be selective skills. That is available through each GIM program for someone with a defined need for the skill but not needed by each graduate. Those skills for which further clarification as to scope of practice is needed are listed in Table 6.

\begin{tabular}{|l|}
\hline Transvenous Pacemaker Insertion \\
\hline Elective Cardioversion \\
\hline Chest Tube Insertion \\
\hline Bone Marrow Aspiration and Biopsy \\
\hline Overnight Oximetry Interpretation \\
\hline
\end{tabular}

meeting to validate and gain further information from an additional cohort. Data were compared across previous studies, electronic survey, consensus conference and written comments collated after the conference (Table 2).

Procedures were then divided into those for which a clear consensus indicated they should be mandatory, selective or elective; and those for which there was divergence of opinion. The final lists and the data behind the areas with lack of consensus were presented to the RCPSC GIM Specialty Committee (national 
standards setting committee) in February 2016. A modified Delphi technique was employed to determine the final category for each procedure.

For those areas without consensus after that meeting there was further online voting. Table 2 summarizes the data obtained from each component.

\section{Results}

The CSIM online survey (fall 2015) had 150 respondents (presumed 127 full members), an 11\% response rate for full members. $48 \%$ of respondents had all subspecialists available in their context; $16 \%$ had none. Respondents came from a diversity of settings: rural, remote, urban, and ambulatory and hospital based. Approximately $28 \%$ were remote or rural, with $72 \%$ urban.

Information was triangulated from multiple data sources to assign procedures as mandatory (Table 3 ) or selective (Table 4). All of the current procedures listed in the internal medicine and GIM objectives (Table 1) were confirmed to be mandatory.

Table 5 illustrates the great diversity of procedures done by general internists in Canada with every procedure surveyed being done by at least one General Internist throughout Canada.

Comments from the CSIM online survey illustrated several main themes applicable to GIM training. There is a need to ensure that graduates who need procedural training for their future practice setting receive adequate training to be competent

Table 5. Diversity of GIM Procedural Skills

Skills representing the diversity of skills that may be required by General Internists in different Canadian settings. Procedural skills that are used by at least one General Internist throughout Canada in their practice.

\begin{tabular}{|l|}
\hline Stress Echocardiography \\
\hline Nuclear Cardiac Imaging \\
\hline Permanent Pacemaker Insertion \\
\hline ICD interrogation/reprogramming \\
\hline Implantable Loop Recorder/Insertion/Removal \\
\hline Sleep Study Interpretation (Level 3) \\
\hline PICC Line Insertion \\
\hline Therapeutic GI Endoscopy \\
\hline Liver Biopsy \\
\hline Thyroid Biopsy \\
\hline Hemodialysis (ICU and Chronic) \\
\hline Peritoneal Dialysis \\
\hline Skin Testing/Allergy Testing \\
\hline Temporal Artery Biopsy \\
\hline Pericardiocentesis \\
\hline Percutaneous Tracheostomy \\
\hline Delivery of Chemotherapy \\
\hline
\end{tabular}

on graduation. At the same time there is a need to avoid dilution of learning opportunities by ensuring that graduates who will actually perform the procedures that they learn through specialized training opportunities have the ability to learn the procedure.

Ultrasound-guided bedside procedures (in particular central venous access, paracentesis, and thoracentesis) were repeatedly noted to merit increased prominence in GIM training. Another theme emerging from the survey was that procedures should not take precedence over ensuring good generalist skills - seeing the "whole" patient, diagnostic skills, outpatient skills. Some respondents commented that general internists should be engaged more heavily in training future graduates in procedures as opposed to leaving this to other subspecialists who may be unwilling/unable to train GIM graduates. Individuals also commented that practice-long maintenance of competence was important; learning skills "just in case" was not a good strategy.

Ultrasound-guided bedside procedures figured prominently in the online CSIM responses. At least 75 respondents took the time to write in various ultrasound-guided bedside procedures as important. The perception was that ultrasound-guided thoracentesis, paracentesis, central line insertion should be learned by GIM graduates.

The validation process by the expert stakeholder group was able to elucidate several areas where further clarification was needed prior to final assignment of a procedure to a category (Table 6). For example, participants did not have a shared mental model as to the definition or level of competency that would need to be obtained for several of the procedures (Table 6) including echocardiography, bronchoscopy, and pacemaker interrogation/reprogramming. This is leading to ongoing discussion and information gathering to define not only which procedures should be learned by GIM graduates, but also the appropriate scope of practice.

Many individuals self- identified with both a rural/remote practice and an urban practice; due to small numbers, it was difficult to correlate practice type with procedural practice. However; of note for those currently performing transvenous pacemaker insertion, over $50 \%$ reported practicing at least part time in an urban centre.

\section{Discussion and Conclusions}

General Internists practice in a wide variety of contexts and practice settings. The final list of procedural skills needed by GIM graduates will vary for each graduate; however, this study managed to solidify a list of mandatory skills for all graduates. A wide array of procedural skills are practiced by general internists across Canada. GIM program directors and GIM graduates need to be aware of this diversity and plan the flexible portion of training accordingly. 
Table 6. Procedures for which Clarification of Level of Expertise is Needed Prior to Assigning to a Final Category

Procedure

\begin{tabular}{|c|c|}
\hline Procedure & Question Remaining \\
\hline Echocardiography & What level of echocardiography should be a selective in each program? Level one, two or three? ${ }^{7}$ \\
\hline Bronchoscopy & $\begin{array}{l}\text { What expertise in bronchoscopy should be available as a selective? Diagnostic? Therapeutic in the ICU? } \\
\text { Other? How should this be assessed? Are there applicable standards for a General Internist learning } \\
\text { bronchoscopy and assessing competence that are relevant? }\end{array}$ \\
\hline Pacemaker Interrogation and Reprogramming & $\begin{array}{l}\text { What are the competencies required in this domain for a selective? How can this be taught and } \\
\text { assessed? Can CSIM build an educational module for this domain? Should it include turning ICD's off? }\end{array}$ \\
\hline Ultrasound Guided Procedures & $\begin{array}{l}\text { Confirm central line, paracentesis and thoracentesis should be ultrasound guided - should others? } \\
\text { Should competency in diagnostic Point of Care Ultrasound be taught? }\end{array}$ \\
\hline Upper and Lower Endoscopy & Should expertise in endoscopy be available as a selective? If so diagnostic or therapeutic? \\
\hline Skin Biopsy & Should it be mandatory or selective? \\
\hline $\begin{array}{l}\text { Joint (non-knee) and Non-articular Aspiration } \\
\text { and Injection }\end{array}$ & $\begin{array}{l}\text { What expertise in this area should be available as a selective in each program? What competency level } \\
\text { should be obtained? What are the specific competency domains under this category? }\end{array}$ \\
\hline
\end{tabular}

Several of the areas had a divergence of opinion because of an identified lack of common understanding regarding the level of competence to which the procedure should be performed by all or some graduates for example echocardiography. (Table 6) The GIM RCPSC Specialty Committee will be exploring these further to develop explicit recommendations for the level of competence for a GIM graduate in any one of these procedures if they become a Selective. As well some of the "procedural skills" on the CSIM survey such as insulin pump downloads have been reintegrated with other medical expert content due to their integral function in the care of patients with diabetes.

As Competence by Design becomes a reality for GIM, there is an ideal opportunity to utilize the transition to practice portion of training to solidify the individualized procedural training skills for each Canadian GIM graduate.

As far as we are aware this is the first effort to triangulate data on Canadian General Internists from the literature, a national specialty society, and the Royal College standard-setting committee. The information gained from both the online survey of members and the large group discussion at CSIM was instrumental in improving training standards for GIM. The linkage between practicing physicians and the educational community brought key insights into training GIM graduates for the future. We are grateful for the participation of the members of the practicing GIM community for participating so readily in this endeavour!

\section{Acknowledgements}

We are grateful to the Canadian Society of Internal Medicine (CSIM) for support in conducting the survey of members and the production of the Round Table in October 2015.
Canadian Society of Medicine (CSIM) is gratefully acknowledged for support of this project. Thanks to Ms. Zoë Stevens-Lavigne, administrative coordinator (CSIM) for survey assistance. All survey participants and the participants of the CSIM Roundtable (2015) are gratefully acknowledged for their participation.

\section{References}

1. Miller DB. Procedural skills: A survey of general internists in British Columbia. Annals RCPSC 1992;25(6):355-7.

2. Soparkar GR, Card SE. Technical skills during residency and in practice: A survey of specialists in internal medicine in Saskatchewan. Annals RCPSC 1999;32(5):296-301.

3. Card SE, Snell L, O'Brien B. Are Canadian general internal medicine training program graduates well prepared for their future careers? BMC Med Educ 2006;6:56:1-9.

4. Card SE, PausJenssen AM, Ottenbreit RC. Determining specific competencies for general internal medicine residents (PGY 4 and PGY 5). What are they and are programs currently teaching them? A survey of practicing general internists. BMC Res Notes 2011;4:480.

5. Royal College of Physicians and Surgeons. The current Royal College documents (objectives of training, specialty training requirements and specific standards of accreditation for Internal Medicine and General Internal Medicine). Available at: http://www.royalcollege.ca/rcsite/home-e. Under examinations - information by discipline, subspecialty - general internal medicine; specialty - internal medicine.

6. Royal College of Physicians and Surgeons. Website - Competence by design. Available at: http://www.royalcollege.ca/rcsite/cbd/ competence-by-design-cbd-e.

7. Canadian Cardiovascular Society. Canadian Cardiovascular Society Guidelines for Echocardiography Training. http://www.ccs.ca/en/ guidelines-library 